\title{
A SENSORLESS SPEED CONTROL USING STATOR RIPPLE CURRENTS FOR AN INDUCTION MOTOR DRIVE WITH SPACE PHASOR PWM
}

\author{
K.K. Mohapatra*, K. Gopakumar*, M.R. Baiju*, Balarama V. Murty *
}

Keywords: Field oriented control, Induction machine, Current ripple

\begin{abstract}
In the present paper a simple sensorless specd estimation scheme is presented, where the speed information is obtained from the motor phase current ripple. The scheme measures the stator current phasor deviation direction to determine the back emf vector position during inverter zero vector switching states. This measurement of rotor flux position is done indirectly by computing the motor back emf position which is orthogonal to the rotor flux position. The space vector PWM voltage output in motor phase generates a current ripple pattern, which depends upon the ripple voltage and equivalent stator leakage inductance. For high speed operation when the time duration for the zero vector switching states are small an indirect method for flux position estimation is proposed, where the effect of active voltage vectors on the stator ripple current is eliminated by creating a virtual short circuit at the motor terminals.
\end{abstract}

\section{Introduction}

Generally field oriented control is used to operate an induction motor for high dynamic performance applications. But to achieve this complicated signal processing costly encoders are required. To avoid use of costly encoders sensorless drives have been proposed which use the stator voltage and current information along with machine model to estimate rotor flux position[1].

Schroedller [2] has proposed a speed sensorless scheme where motor stator current phasor deviation vectors are used for estimation of flux position. This scheme [2] uses conventional current hysteresis control for PWM generation. In reference [3] a field oriented control scheme with rotor flux position estimation and stator leakage impedence estimation is proposed where a space phasor based current hysteresis controller is used for PWM generation[4]. But any current hysteresis controller has its limitation of randomness and high unpredictable switching frequency.

In this work a rotor flux estimation scheme for an induction motor drive is proposed which uses the current space phasor ripple in a constant switching frequency based space vector PWM drives. Thereby the problems associated with random and high PWM switchings are avoided.

In the proposed scheme at lower modulation indices current space phasor deviations are sampled during zero inverter vector states and hack emf position is estimated from the current space phasor deviation vector direction. At high speed of operation the zero vector period are small hence make it difficult to sample the current space phasor change in the same zero vector period. An alternate scheme is proposed for high speed region, where two neighbour current space phasor deviation vectors of a fixed sampling period are sampled in a switching period. The two sampled current space phasor deviation'vectors contain the effect of active voltage vectors in addition to the motor back emf vectors. By using proper linear transformation between those two consecutive current deviation vectors, the effect of active inverter switching voltage vectors can be nullified, thereby creating a virtual short circuit, identical to the zero vector state in low speed region of operation. From this modified stator current equations, the information of the back emf position is extracted. The rotor flux estimation scheme is presented in the following section.

\section{Rotor Flux Position Detection During Zero Vector Period :}

As the rotor flux vector $\left(\underline{\Psi_{\Gamma}}\right)$ always lags by $\pi / 2$ from the back emf vector $\left(V_{m}\right)$, the rotor flux vector position can he estimated once the back emf vector position is estimated. In space vector modulation, when zero vectors are impressed across the stator windings, from the rotor flux oriented stationary reference frame model, the rate of change of stator current can be written as 


$$
\frac{d \underline{i_{s}}}{d t}=-\frac{V_{m}}{l_{\sigma}}-\frac{i_{\underline{s}} r_{s}}{l_{\sigma}}
$$

$\underline{V_{m}}=$ Machine back emf vector, $\underline{i}_{\underline{s}}=$ Stator current space phasor, $l_{\sigma}=$ Stator leakage inductance, $r_{s}=$ Stator resistance. For the present work (constant switching frequency space phasor based PWM), for modulation indices less than 0.5 , the hack emf vcctor position estimation is achieved using eqn.\}. To get sufficient current space phasor change during zero vector periods two samples of current space phasor are taken during two consecutive zero vector periods, by taking the first sample during the zero vector period at the end of an inverter sampling period and the next sample at the starting zero vector period of the next inverter sampling period. Since a constant switching frequency PWM scheme is used, the duration between two consecutive current samples is chosen as $T / 2$ ( $T$ is the PWM switching period) for modulation indices less than 0.5 .

From equation.1

$$
\frac{V_{m}}{l_{\sigma}}=-\frac{i_{s k+1}-i_{s k}}{(T / 2)}-\frac{i_{s k} r_{s}}{l_{\sigma}}
$$

Where

$$
\Delta \underline{\underline{i_{s}}}=\underline{i_{s k+1}} \cdot \underline{i_{s k}}
$$

$i_{s k}=$ The sampled current phasor at $\mathrm{k}^{\text {th }}$ instant

$\underline{i_{s k+1}}=$ The sampled current phasor at $(\mathrm{k}+1)^{\text {th }}$ instant and $(\mathrm{k}+1)^{\mathrm{th}}$ instant $=\mathrm{k}^{\mathrm{th}}$ instant $+T / 2$

From equation.2 the argument of vector $V_{m}$ can be found out which give the back emf position. The rotor flux always lags the hack emf by $\pi / 2$. When the phasors are making clockwise rotation in space the rotor flux vector position is obtained by subtracting $\pi / 2$ from the hack emf vector position and when the phasor quantities are making anti-clockwise rotation in space the rotor flux vector

\section{Rotor Flux Position Detection During High Speed Operation :}

At higher speed of operation (modulation index $>0.5$ ) as hack emf magnitude increases the effective period $\left(T_{e f f}\right)$ becomes larger and this results in smaller zero vector period $T_{0}$. Hence it becomes difficult to sample error currents during the zero vector period. At any instant, the reference voltage space vector $\left(\underline{V_{S}}\right)$ in a sector is realized by two nearest adjacent active voltage vectors and zero vector. Fig. I shows the different voltage vectors and the current phasor w.r.t. time in a sampling period $T$.

$T_{1} \quad=$ Period when active voltage vector $V_{1}$ is switched
$T_{2}=$ Period when active voltage vector $V_{2}$ is switched.

$T_{e f f}=$ The effective period of both active voltage vector $V_{1}$ and $V_{2}$.

$i_{\text {sk }}=$ Sampled current at the beginning of the sampling period ( $\mathrm{k}^{\text {th }}$ instant).

$\underline{i_{s k+1}}=$ Sampled current at the middle of the sampling period $\left(\mathrm{k}+1^{\text {th }}\right.$ instant).

$\underline{i_{s k+2}}=$ Sampled current at the end of the sampling period $\left(\mathrm{k}+2^{\text {th }}\right.$ instant).

$i_{\text {orr }}=$ Change in current space vector in the first half of the sampling period.

$$
\underline{i}_{\text {err } 1}=\underline{i_{s k+1}}-\underline{i_{s k}}
$$

$i_{\text {err } 22}=$ Change in current space vector in the second half of the sampling period.

$$
\underline{i_{\text {err } 2}}=\underline{i_{s k}+2-i_{s k+1}}
$$

$$
\text { In any sector, when } \theta<30^{\prime} \quad\left(T_{l}>T_{2}\right. \text {, Fig. la) }
$$$$
\underline{i_{e r r 1}}=\frac{1}{l_{\sigma}}\left(V_{1} \times T_{e f f} / 2-\underline{V_{m}} \times T / 2\right)
$$

$$
\begin{aligned}
\underline{i_{\text {err } 2}=} & \frac{1}{l_{\sigma}}\left\{\underline{V_{1}} \times\left(T_{e f f} / 2-T_{2}\right)\right. \\
& \left.+\underline{V_{2}} \times T_{2}-\underline{V_{m}} \times T / 2\right\}
\end{aligned}
$$

In any sector, when $\theta>30^{\circ} \quad\left(T_{1}<T_{2}\right.$, Fig.1 b $)$

$$
\begin{gathered}
\underline{i_{\text {err } 1}=\frac{1}{l_{\sigma}}\left\{\underline{V_{1}} \times T_{1}\right.}+\underline{V_{2}} \times\left(T_{e f f} / 2-T_{1}\right) \\
\left.-\quad \underline{V_{m}} \times T / 2\right\} \\
\underline{i_{\text {err } 2}}=\frac{1}{l_{\sigma}}\left(V 2 \times T_{e f f} / 2-V_{m} \times T / 2\right)
\end{gathered}
$$

Eqn.(6) to eqn.(9) shows that sampled current deviation vector contains information regarding hack emf vector $V_{m}$. But to extract the back emf vector $V_{m}$ position information, the effect of adjacent active voltage vectors $\left(\underline{V_{1}}, \underline{V_{2}}\right.$ in sector-1) need to be removed. The active voltage vectors $\underline{V_{1}}$ and $\underline{V_{2}}$ are related as

$$
\underline{V_{2}}={\underline{V_{1}}}^{j \pi / 3}
$$


Using equations (6),(7)and (I0), the hack emf vector $V_{m}$ ( when $\theta<30^{\prime}$ ) as below ;

$$
\begin{aligned}
& \left\{\left(T_{\text {eff }} / 2-T_{2}\right)+e^{j \pi / 3} \times T_{2}\right\} \times \underline{i_{\text {err } 1}} \\
& -T_{\text {eff }} / 2 \times \underline{i_{\text {err } 2}} \\
& =\frac{1}{l_{\sigma}}\left(V_{m} \times T / 2\right) \times\left\{e j \pi / 3 \times T_{2}-T_{2}\right\}
\end{aligned}
$$

Similarly when $\theta>30^{\prime}$ by substituting eqn.(10) in eqn.(8) and by eliminating vector $V_{2}$ from eqn.(8) and eqn.(9) hack emf position information can be found out. But from practical implementation point of view the current deviation phasors are small in magnitude and have high noise content. Therefore extraction of back emf information is not feasible by this direct method.

In the proposed method the current deviation vector $i_{\text {err } 1}$ and $i_{\text {err } 2}$ are filtered to remove the noise content. High Q-factor hand pass filters with center frequency at the fundamental frequency will remove the noise and other unwanted harmonics from the current deviation vector. The filter output contains only the fundamental component of active vectors and that of hack emf vectors. Let $i_{e r}$ actvel he the current deviation vector component due to active voltage vector $\left(\underline{V_{1}}, \underline{V_{2}}\right)$ in the current deviation vector $\underline{i}_{e r r 1}$ and $i_{e r}$ actve2 he the current deviation vector component due to active voltage vectors $\left(\underline{V_{1}}, \underline{V_{2}}\right)$ in the current deviation vector $i_{\text {err } 2}$ (Fig.1). If $i_{e r}$ acivel and $i_{e r_{\text {actve }}}$ are plotted when the hack emf vector moves $0^{\circ}$ to $360^{\prime}$ they resemble as shown fig. 2 (The analysis will he presented in the final paper). Both figures of fig. 2 are symmetric with respect to a-c, h-a, c-b axes. If $i_{\text {erf_actvel }}$ is the fundamental component of $i_{e r_{2} \text { actvel }}($ fig.2.) and $i_{\text {erf_actvel }}$ is the fundamental component of i_actve2 (fig.2), it can he shown that,( Analysis will be presented in final paper)

$$
{\underline{i_{\text {erf_actvel }}}}^{-=} \underline{-i}_{\text {erf_actve } 2} e^{-j 32.3^{0}}
$$

The fundamental components of eqn.(6) to eqn.(7) can he written as

$$
\underline{i_{\text {err } 1 f}}=\underline{i_{\text {erf _actuel }}}-V_{m f}
$$

$i_{\text {err } 1 f}=$ The fundamental components of the current deviation phasor in first sampling period..
$\underline{V_{m f}}$

$=$ The fundamental components of the current deviation phasor contributed by hack emf in the first and second sampling period.

Similarly the fundamental components of eqn.8 to eqn. 9 can he written as

$$
\underline{i_{\text {err } 2 f}=i_{\text {erf_actve } 2}}-\underline{V_{m f}}
$$

$i_{\text {err } 2 f}=$ The fundamental components of the current deviation phasor in second sampling period..

Now substituting eçı. 12 in eqn. 13 and equating the result with eqn.(14) we obtain eqn.(15)

$$
V_{m f}=\frac{i_{e r r 1 f}-\underline{i}_{e r r 2 f} e^{-j 32.3^{0}}}{\left(e^{-j 32.3^{0}}-1\right)}
$$

The rotor flux position can he estimated from eqn. 15 , by adding or subtracting $\pi / 2$ as explained earlier.

\section{Implementation And Experimental Results:}

The above mentioned scheme is implemented in a TMS3201f2407 DSP hoard. The TMS3201f2407 DSP has $0.57 \mu \mathrm{sec}$ AD-converters to support fast sampling of ripple currents in a switching period. Fig.10 shows the block diagram of the implemented scheme. The flux position estimation block gives the position of rotor flux from the current phasor deviation vector according to the principle described in earlier section. Three consecutive current samples during low speed region of operation or two consecutive current samples during high speed region of operation for two phases are sampled in a switching period. To ensure the synchronization between switching period and current sampling period two interrupt based routines are used. The main interrupt period of the routine whose time period is equal to the switching period of PWM executes all the internal blocks of the sensorless control algorithm. The other interrupt period is equal to the sampling interval of the currents and is used for sampling phase currents. The flux position estimator block estimates the position of flux from the current deviation vectors.(eqn.2 and eqn.15). In the 3 phase to $\mathrm{d}-\mathrm{q}$ transformation block the phase current vector is decomposed into flux axis current component $\left(I s d_{\text {est }}\right)$ and torque axis current component $\left(I s q_{e s t}\right)$. The slip estimator block calculates the motor slip speed $\left(W_{\text {slip }}\right)$ from $I s d_{\text {est }}$ and $I s q_{\text {est }}$ following eqn.6.30.

$$
\begin{aligned}
W_{\text {slip }} & =\frac{I s q_{\text {est }}}{\tau_{r} \times I_{s} d_{\text {est }}} \\
W_{\text {slip }} & =\text { Slip speed } \\
\tau_{r .} \quad & =\text { Rotor leakage time constant }
\end{aligned}
$$


Eqn. 16 gives the estimated slip frequency in the slip calculation block. The slip frequency is subtracted from the synchronous frequency and the result is fed to a low pass filter to give the estimated speed. When by any means there is disorientation and the speed estimation is not correct, the actual Vif ratio no longer matches the reference $\mathrm{V} / \mathrm{f}$ ratio. A compensator block with threshold is added to the speed estimation block to keep the error betweet actual $\mathrm{V} / \mathrm{f}$ ratio and reference $\mathrm{V} / \mathrm{f}$ ratio within $10 \%$ pu

After getting the speed information from the speed estimation block it is fed back to the speed controller block for speed control The speed controller block gives the command torque current $I s q$ and from $I s q{ }^{*}$ the command slip $W_{\text {slip }}{ }^{*}$ is calculated. Estimated speed $W_{m f b}$ is added to the command slip $W_{\text {slip }}^{*}$ to

calculate the synchronous frequency $W_{S}$. During acceleration the command slip $W_{\text {slip }}^{*}$ does not match actual slip $W_{\text {slip }}$. During this period the motor operates in a feedforward mode with current control. The low pass filter used for speed estimation is slow compared to the PI regulator of the current controller. When the motor operates in steady state command slip $W_{\text {slip }}^{*}$ matches actual slip $W_{\text {slip }}$. The flux axis current controller block and the torque axis current controller block generate voltage commands in synchronous reference frame for the motor. Then the general transformations are used to generate 3-phase command voltages $\left(V_{a}, V_{b}\right.$ and $\left.V_{c}^{*}\right)$ for the motor.

The whole scheme is experimentally verified in a $7.5 \mathrm{~kW}$ drive by using TMS320LF2407 DSP based board. Two hall effect Sensors were used to sense the motor phase currents and the current deviations in a sampling period were obtained by subtracting two consecutive sampled currents from each other. The position of flux was estimated by manipulating the current deviation vectors algebraically, as described in earlier part. Fig. 3 shows the position of rotor flux along $\alpha$ - axis and $\beta$ - axis at 10 hertz of operation. As described before at 10 hertz the flux position estimation is obtained from the current deviation vectors sampled in the zero vector period. Fig.4 and Fig.5 show the rotor flux positions along $\alpha$ - axis and $\beta$ - axis for 30 hertz and 40 hertz of operation respectively. The reference speed and estimated speed are plotted in Fig.6 for a speed reversal from 1200 $\mathrm{rpm}$ to $\mathbf{- 1 2 0 0} \mathrm{rpm}$. It can he observed that the estimated speed follows the reference speed. It can he noted that there is some discrepancy in actual command speed and estimated speed at zero speed region. In Fig.7a and Fig.7b are shown the phase current waveform and estimated speed in the speed reversal operation. It can be observed that there is smooth reversal of speed. And in the acceleration part the current magnitude changes. To test for acceleration the drive was accelerated from $400 \mathrm{rpm}$ to $1200 \mathrm{rpm}$. During acceleration the q-axis currents ( Torque component of current) increases as evident from Fig.8. Fig.9 shows the frequency and amplitude variations in phase current as motor accelerates from $400 \mathrm{rpm}$ to $1200 \mathrm{rpm}$.

\section{Conclusions:}

A novel rotor flux position estimation scheme was is proposed and experimental results are presented. The rotor flux position is estimated from the current deviation vectors in a sampling period and hence the phase error in flux position due to integration of voltage in traditional methods is avoided. The proposed method uses a constant switching frequency space vector based PWM. At low speed range of operation the error currents in zero vector periods are used and higher speed of operation a scheme is used to estimate the flux position from the fundamental components of the error current vector.

\section{References:}

[1] Kaushik Rajashekara, Atsuo Kawamura, Kouki Matsuse, " Sensorless control of AC motor drives, - Speed and position sensorless operation", IEEE Press, IEEE Industrial Electronics Society, sponsor.

[2] M. Schroedl, R.S. Wieser," E.M.F. based rotor fluxx detection in induction motors using virtual "short circuits", IEEE Conf. IAS-96, pp.229-233.

[3] V . Ehenezer, K. Gopakumar, V.T.T. Ranganathan, "A sensorless vector control scheme for induction motors using a space phasor bašed current hysteresis controller", EPE Journal. Vol.9, no.3-4, Jan. 2000, pp.41-46.

[4] V. Mistry, S:P. Waikar, L. Umanand, K. Gopakumar, V.T. Ranganathan," A multi axis space phasor based current hysteresis controller for PWM inverters", Int. Conf. IEEE PEDS- 97, Singapore-1 $997, \mathrm{pp} .480-486$. 


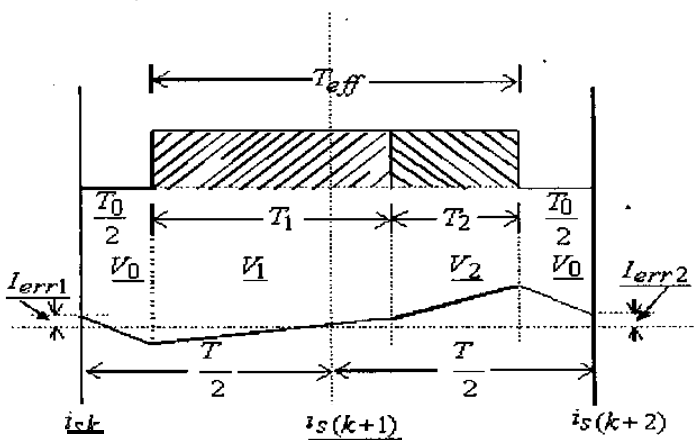

Kig. Ia: voltage vectors and ripple current w.r.t. time

(in a sector) in a sampling period when

reference voltage vector position $\theta<30^{\prime}$.

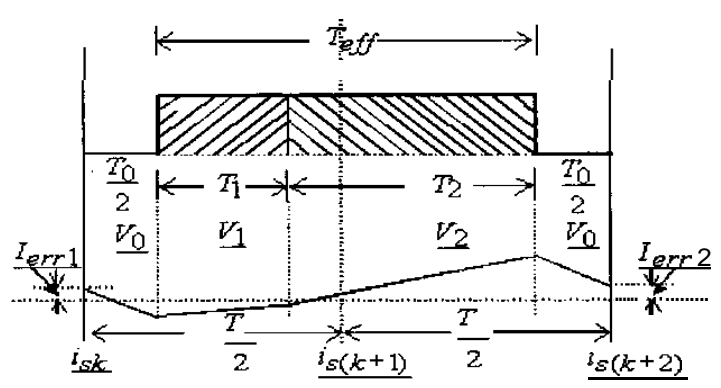

Fig.1b : Voltage vectors and ripple current w.r.t. time (in a sector) in a sampling period when reference voltage vector position $\theta>30^{\circ}$.

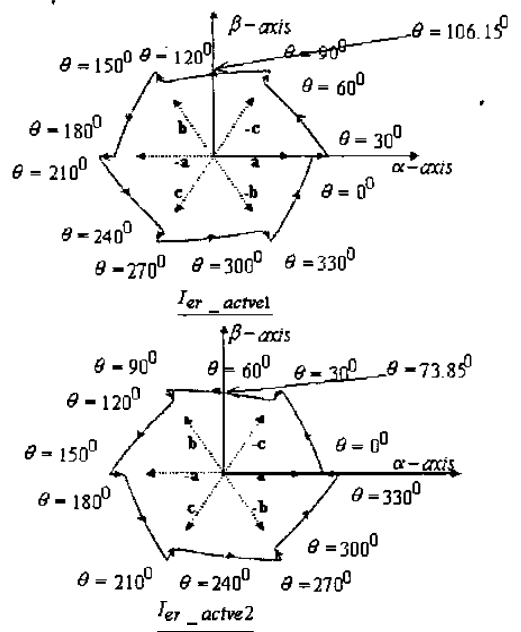

Fig. 2 :Current error phasor I,,_actve1 and $\mathrm{I}_{\mathrm{er}}$ actve 2 as reference voltage vector moves from $0^{0}$ to $360^{0}$

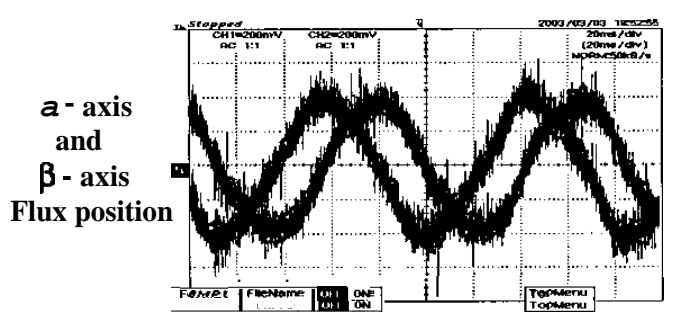

Fig. 3 :Flux position at frequency equal to 10 hertz.

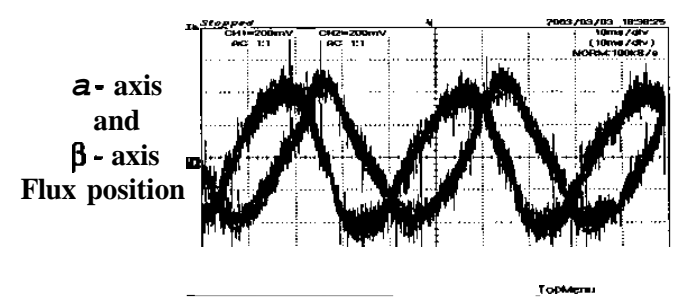

Fig .4 :Flux position at frequency equal to $\mathbf{3 0}$ hertz

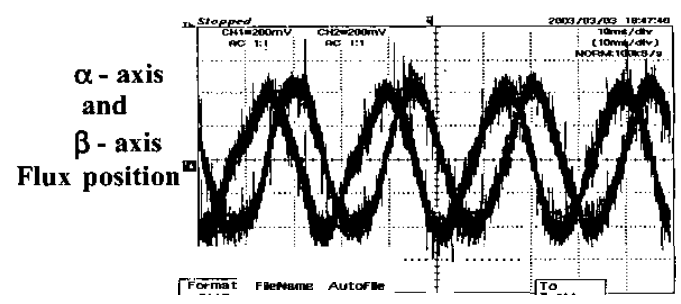

Fig. 5 : Flux position at frequency equal to 40 hertz.

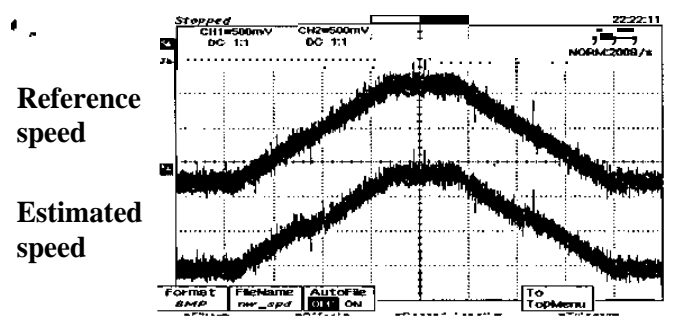

Fig. 6 : Reference speed and estimated speed for speed reversal application. Speed scaling $=800 \mathrm{rpm} / \mathrm{div}$ 


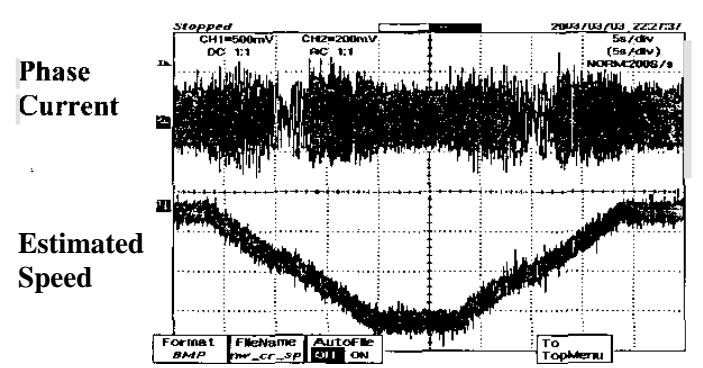

Fig. $7 \mathbf{a}$ :Phase current and estimated speed for speed reversal application.

Current $=5 \mathrm{~A} / \mathrm{div}$, Speed $=800 \mathrm{rpm} / \mathrm{div}$

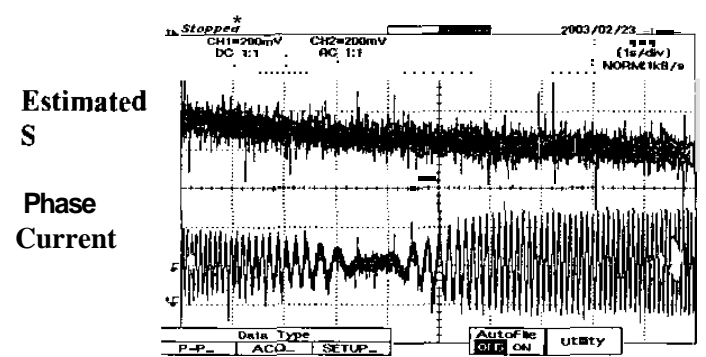

Fig. 7b : Phase current and estimated speed for speed reversal application.

Current $=5 \mathrm{~A} / \mathrm{div}$, Specd $=800 \mathrm{rpm} / \mathrm{div}$

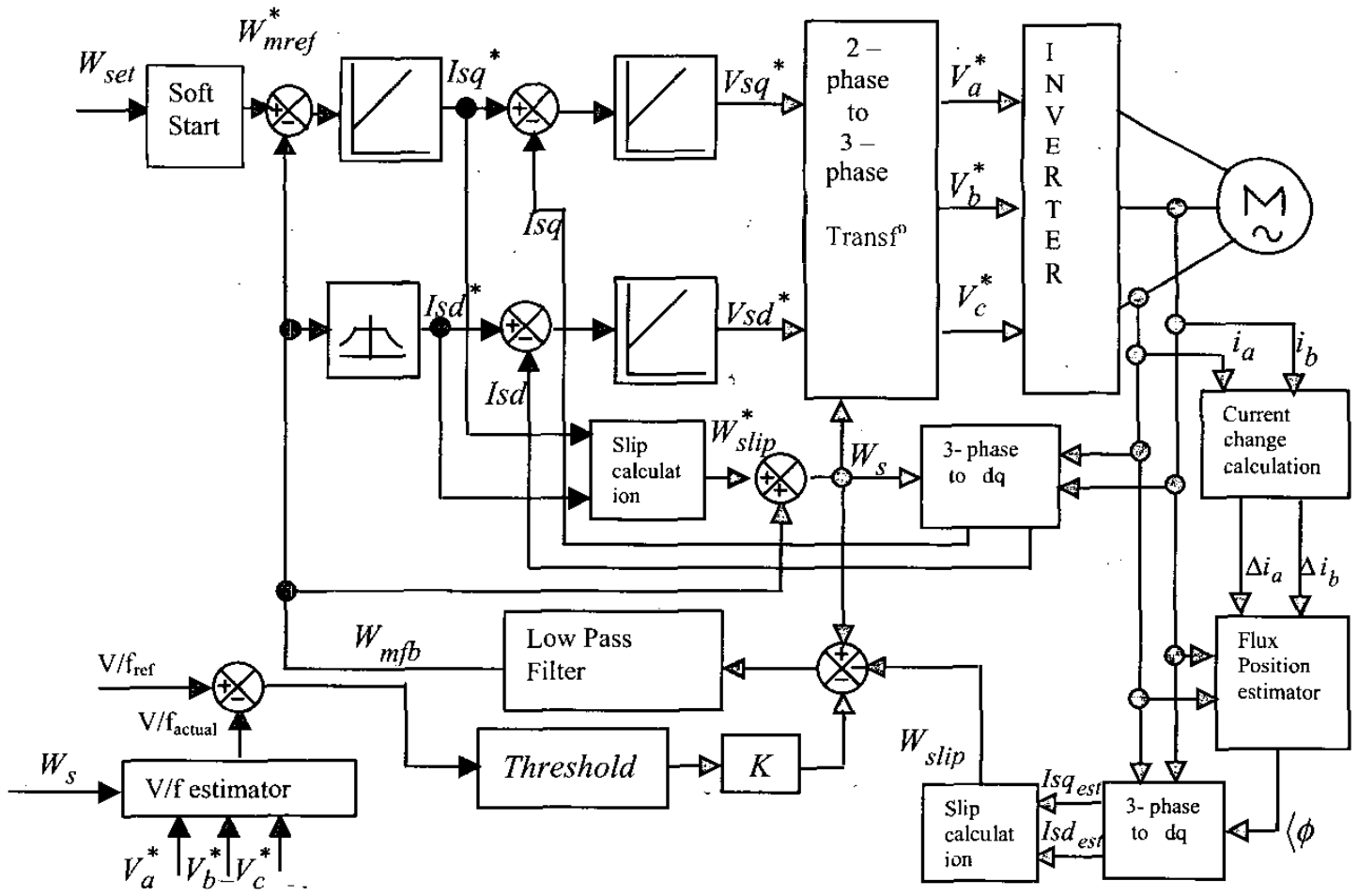

Fig.10 :Block diagram of sensorless speed control scheme
Estimated

Speed

Torque

Current
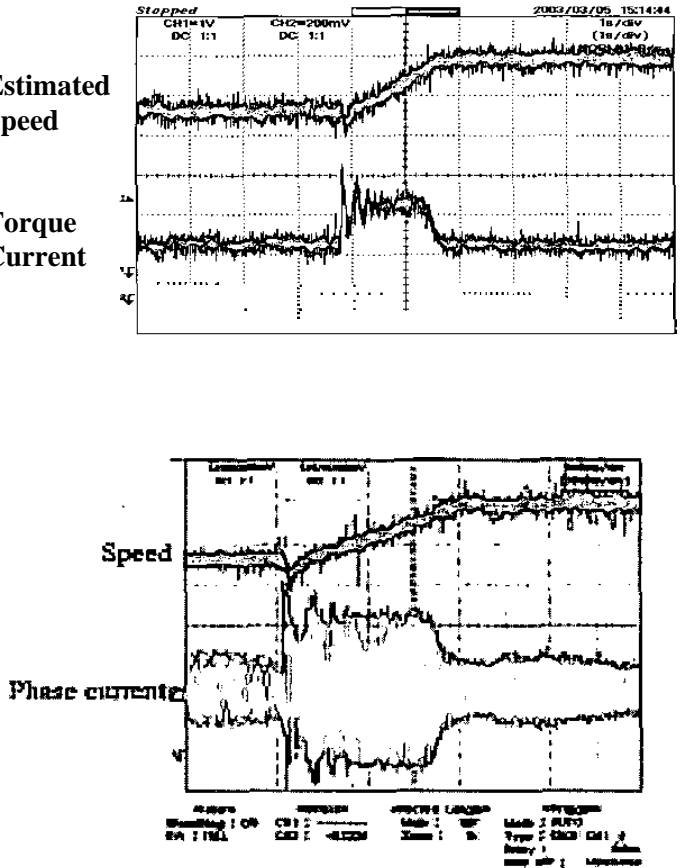

Fig.9 :Phase current and estimated speed during acceleration. Current scaling $=5 \mathrm{~A} / \mathrm{div}$, Speed scaling $=600 \mathrm{rpm} / \mathrm{div}$ 